\author{
Д.О. Добровольский \\ Институт русского языка им. В. В. Виноградова РАН, \\ Институт языкознания РАН \\ (Россия, Москва) \\ dobrovolskij@gmail.com
}

\title{
«ПОКАЗАТЕЛИ БЕЗРАЗЛИЧИЯ» В РУССКО-НЕМЕЦКОМ КОРПУСЕ ПАРАЛЛЕЛЬНЫХ ТЕКСТОВ*
}

Цель данного исследования - выявить на основе анализа корпусных данных, насколько интуитивные представления об эквивалентности структурно схожих немецких и русских конструкций соответствуют их реальному употреблению. В качестве материала используются данные русско-немецкого и немецко-русского параллельных корпусов НКРЯ. Анализируются контексты с такими конструкциями, как родственники родственниками, но.., мнения мнениями, а..., то есть фразами, структурно основанными на паттерне $[\mathrm{P}(\mathrm{X} \mathrm{X}-о м)$, но/a $\mathrm{Q}]$ и обладающими специфической семантикой. Несколько огрубленно такие конструкции можно охарактеризовать как «показатели безразличия», поскольку, употребляя эту структуру, говорящий как бы выводит сущность $\mathrm{X}$ из сферы релевантных объектов обсуждения. При этом на первый план может выходить идея снижения значимости аргумента собеседника или несогласие с его предложением, чисто уступительное значение или равнодушие говорящего по отношению к объективным обстоятельствам. На первый взгляд паттерн $[\mathrm{P}(\mathrm{X} \mathrm{X}-о м), н о / a \mathrm{Q}]$ имеет в немецком языке хороший, то есть близкий и по форме, и по значению, эквивалент, в основе которого лежит фразеологизм, - конструкцию [X hin, X her]. Обращение к параллельному корпусу позволило сделать вывод об отсутствии стабильной эквивалентности между этими конструкциями. Их параллельное употребление в аутентичных контекстах крайне нетипично. Причины отсутствия функциональной эквивалентности анализируются в статье.

Ключевые слова: параллельный корпус, лексическая семантика, конструкции, межъязыковая эквивалентность, русский язык, немецкий язык.

Современное состояние параллельных корпусов НКРЯ позволяет постепенно начинать исследовать явления, относительно редко встречающиеся в текстах. Тема настоящей работы - сопоставление некоторых идиоматичных способов выражения безразличия в русском и немецком языках. Изучению выражений русского языка с семантикой 'безразлично А или не-А, потому что В' и их английских эквивалентов посвящена работа [Голубцов 1999]. В ней описываются, с одной стороны, такие грамматические фразеологизмы, как мало ли, все равно, а с другой - восклицательные и вопросительные высказывания типа Что за дело/беда!, Ну и что?,

* Работа выполнена в рамках Программы фундаментальных исследований Президиума РАН «Памятники материальной и духовной культуры в современной информационной среде» по проекту «Пополнение и развитие корпуса параллельных текстов в составе НКРЯ». 
A мне-то что? и идиомы разной структуры до лампочки, до фонаря, один черт, хозяин - барин, в том числе речевые формулы вольному воля, где нама не пропадала, семь бед - один ответ. В качестве английских коррелятов рассматриваются такие выражения, как it is all the same (to me), it's all one to me; it is the same thing; it is the same damned thing; it comes to the same damn thing, it doesn't make any difference, What's the difference?, there's no point in it; that is nothing to me; it is no business/ concern of mine; I am not concerned; it is not my problem/affair; it doesn't refer to me.

В данной статье нас интересуют несколько другие выражения. Так, формы [P(X X-ом $),$ но/a $\mathrm{Q}],[\mathrm{P}($ хоть $\mathrm{X}$, хоть не-X), (а) $\mathrm{Q}]$ или [P(что $\mathrm{X}$, что не-X), (a) $\mathrm{Q}]$ хорошо вписываются в группу конструкций с базовой семантикой безразличия. Ср.: Дождь дождем, а я все равно пойду гулять или Хоть отпуск, хоть не отпуск, а работу все равно надо будет сдать в срок или Что воля, что неволя... Формы [Х $\mathrm{X}-о м],[х о т ь ~ \mathrm{X}$, хоть не-X] и [что $\mathrm{X}$, что не-X] синонимичны выражениям типа Что за дело/беда, что Х, Ну и что, что Х? и соответствуют формуле 'безразлично А или не-А, потому что В', предложенной в [Голубцов 1999].

Наряду с семантикой безразличия интересующие нас конструкции обладают уступительно-противительным значением; ср. [Булыгина, Шмелев 1997; Шмелев 2002; Апресян 2015]. Валентина Апресян [Апресян 2015: 60] указывает на полемический потенциал подобных выражений, предполагающих несогласие с аргументами собеседника. Их значение можно приблизительно описать так: 'хотя ты и говоришь, что $\mathrm{X}$ имеет место и, возможно, является для тебя значимым фактором, для меня X несущественен и не является препятствием для Р'. Естественно, эта схема значения весьма приблизительна и может модифицироваться в конкретных контекстных условиях. На первый план может выходить идея снижения значимости аргумента собеседника или несогласие с его предложением, чисто уступительное значение или равнодушие говорящего по отношению к объективным обстоятельствам. Таким образом, отнесение этих выражений к «показателям безразличия» до некоторой степени условно.

С одной стороны, достаточно очевидно, что эти выражения характеризуются определенной лингвоспецифичностью. С другой - не менее очевидно, что выражаемые ими смыслы в силу их коммуникативной значимости должны выражаться и в других языках. На первый взгляд в немецком языке у русских конструкций [P(X X-ом), но/а $\mathrm{Q}],[\mathrm{P}($ хоть $\mathrm{X}$, хоть не-X), (а) $\mathrm{Q}]$ и [P(что $\mathrm{X}$, что не-X), (а) $\mathrm{Q}]$ есть хорошие системные эквиваленты. Паттерн [X X-ом] коррелирует с немецким фразеологизмом-конструкцией ${ }^{1}$ [X hin, X her]; cp.: Krise hin, Krise her. Doch eine genauere Analyse zeichnet ein anderes Bild. - Кризис кризисом, а более точный анализ дает другую картину. Конструкциям с повторяющимися хоть и что соответствуют немецкие конструкции с союзом ob. Ср.: Ob Krise, ob nicht, ob mit Kindern oder ohne. - Хоть кризис, хоть не кризис, хоть с детьми, хоть без. $\approx$ Что кризис, что не кризис, что с детьми, что без.

${ }^{1}$ О классе фразеологизмов-конструкций (англ. constructional phrasenes, нем. PhrasemKonstruktionen) cм. [Dobrovol'skij 2011; 2015; Баранов, Добровольский 2013; Добровольский 2016]. 
Соответствующие русские и немецкие конструкции схожи не только семантически, но и по предпочтениям в заполнении свободного слота. Так, русское выражение, построенное по схеме [X Х-ом], однозначно требует заполнения позиции Х существительным, причем и первый (существительное в именительном падеже), и второй слот (существительное в творительном падеже) должны обязательно заполняться одним и тем же существительным. На аналогичные ограничения в заполнении слота Х немецкой конструкции [X hin, $\mathrm{X}$ her] неоднократно указывалось в специальной литературе [Černyševa 1986: 213; Fleischer 1997: 132] ${ }^{2}$. Напротив, русские конструкции с хоть или что и их немецкие аналоги с $o b$ допускают в позиции X разные слова без ограничений на их частеречную принадлежность: $O b$ dieses, ob jenes, kommt auf eins hinaus. — Что то, что это <хоть то, хоть это > — все равно кончится одним и тем же. Ср. также пример (1) из русско-немецкого параллельного корпуса НКРЯ:

(1) И! Пахомовна, у нас что свисти, что нет: а денег все нет как нет. [А. С. Пушкин. Дубровский (1832-1833)]

Ih! Pachomowna, ob bei uns gepfiffen wird oder nicht: Geld ist niemals da. [Alexander Puschkin. Dubrowskij (Arthur Luther, Michael Pfeiffer, 1984)]

Цель данного исследования - выявить на основе анализа корпусных данных, насколько интуитивные представления об эквивалентности структурно схожих немецких и русских конструкций соответствуют их реальному употреблению. В этой статье мы сконцентрируемся на функционировании конструкции [P(X X-oм), но/a $\mathrm{Q}]$ и ее немецких соответствий.

Обратимся к русско-немецкому параллельному корпусу. При поиске были заданы следующие параметры:

Слово1 Грамм. признаки: S,nom

Слово2 Грамм. признаки: S,ins

Слово2 Доп. признаки и языки: lexred

В результате поиска были собраны контексты, в которых форма существительного в творительном падеже непосредственно следует за формой того же существительного в именительном падеже. После исключения из материала примеров с омонимичными конструкциями типа дурак дураком и взаимного местоимения

\footnotetext{
2 Анализ материала корпуса DeReKo показал, что данные ограничения не существенны для современного употребления конструкции [X hin, X her]. В немецкоязычных корпусах встречаются случаи, когда позицию $\mathrm{X}$ занимают слова других частей речи; ср. einverstanden hin, einverstanden $h e r$, что можно перевести на русский язык как согласиться-то можно, но... или согласен-то я согласен, но... Что касается требования заполнения слота X идентичным словом, оно также не соблюдается. По данным корпуса DeReKo, больше половины употреблений этой конструкции обнаруживают разные слова в позиции перед hin и her. Ср.: Schauer hin, Graupel her, das Spiel findet statt. $\approx$ Хоть ливень, хоть град - матч всё равно состоится. В дальнейшем нас будут интересовать только случаи заполнения слота Х идентичным существительным, так как только в этих случаях ожидается потенциальная эквивалентность форм [X hin, $\mathrm{X}$ her $]$ и [X Х-ом].
} 
друг другом остались единичные контексты (2)-(5). Несмотря на их немногочисленность, эти примеры позволяют обнаружить определенную тенденцию: ни один из контекстов с конструкцией [P(X X-oм), но/a Q] не переводится на немецкий язык с помощью конструкции с формой [X hin, X her], хотя эта форма, казалось бы, полностью эквивалентна русскому паттерну [X X-ом].

(2) - Надеюсь увидать вас еще, но надеюсь тоже, что вы перемените свои мнения, мой милый мсье Пьер, - сказала она. Когда она сказала ему это, он ничего не ответил, только наклонился и показал всем еще раз свою улыбку, которая ничего не говорила, разве только вот что: «Мнения мнениями, а вы видите, какой я добрый и славный малый». И все, и Анна Павловна невольно почувствовали это. [Л.Н. Толстой. Война и мир, том 1 (1865-1869)]. «Ich hoffe Sie nun öfter zu sehen, aber ich hoffe auch, daß Sie Ihre Meinungen ändern werden, mein lieber Monsieur Pierre.» Pierre antwortete nichts darauf, verneigte sich nur und zeigte noch einmal allen sein Lächeln, das nichts anderes besagte als höchstens: Es gibt nun einmal verschiedene Meinungen, aber Sie sehen ja, was für ein guter und prächtiger Junge ich bin. Und alle, auch Anna Pawlowna, fühlten das. [Lew Tolstoi. Krieg und Frieden (1. Band) (Hermann Röhl, 1922)].

(3) - Да что ж пенька? Помилуйте, я вас прошу совсем о другом, а вы мне пеньку суете! Пенька пенькою, в другой раз приеду, заберу и пеньку. [Н.В. Гоголь. Мертвые души (1835-1852)].

„Was soll ich mit dem Hanf? Du lieber Gott, ich bitte Sie um etwas ganz anderes, und Sie bieten mir Hanf an! Lassen wir den Hanf Hanf sein, wenn ich ein andermal vorbeikomme, nehme ich auch den Hanf.“ [Nicolaj Gogol. Die toten Seelen (Michael Pfeiffer, 1978)]

(4) Генерал Бетрищев, близкий приятель и, можно сказать, благотворитель, просил навестить родственников... Конечно, родственники родственниками, но отчасти, так сказать, и для самого себя: ибо видеть свет, коловращенье людей - кто что ни говори, есть как бы живая книга, вторая наука. [Н. В. Гоголь. Мертвые души (1835-1852)].

Der General Betrischtschew, ein naher Freund und, ich darf wohl sagen, mein Wohltäter, bat mich, seine Verwandten aufzusuchen? Natürlich, die Verwandten sind wichtig, doch ich reise zum Teil sozusagen auch zum eigenen Vergnügen: Denn die Bekanntschaft mit der Welt und dem Treiben der Menschen — da sage einer, was er will, das ist wie ein lebendes Buch, wie eine zweite Wirtschaft. [Nicolaj Gogol. Die toten Seelen (Michael Pfeiffer, 1978)]

А если видишь еще, что всё это с какой целью творится, как вокруг тебя всё множится да множится, принося плод да доход. Да и я рассказать не могу, что тогда в тебе делается. И не потому, что растут деньги. Деньги деньгами. Но потому, что всё это дело рук твоих; потому, что видишь, как ты всему причина, ты творец всего, и от тебя, как от какого-нибудь мага, сыплется изобилье и добро на всё. [Н. В. Гоголь. Мертвые души (1835-1852)]. 
Und wenn man dann noch sieht, zu welchem Ziel dies alles geschaffen wird, wie sich ringsum alles mehrt und mehrt, Früchte trägt und Gewinn bringt... Ich kann gar nicht erzählen, wie einem da zumute ist. Und nicht deshalb, weil das Geld zunimmt. Das Geld ist nicht das Wichtigste. Sondern deshalb, weil all dies das Werk deiner Hände ist, weil du siehst, daß alles von dir ausgeht, daß du der Schöpfer von allem bist und wie ein Zauberer Überfluß und Wohlstand verteilst. [Nicolaj Gogol. Die toten Seelen (Michael Pfeiffer, 1978)].

Вопрос, почему при наличии столь близкого системного эквивалента переводчики предпочитают другие способы передачи этого смысла, достаточно сложен. Проще всего было бы списать это на ограниченность корпусных данных и признать отсутствие переводческой эквивалентности ${ }^{3}$ артефактом анализа. Тем более, что три из четырех проанализированных примеров взяты из одного произведения, переведенного одним переводчиком - М. Пфайфером. В такой ситуации естественно предположить, что выбор эквивалента в значительной степени продиктован индивидуальными вкусами переводчика. Это предположение сталкивается, однако, с возражениями двух типов. Во-первых, как будет показано ниже, отсутствие переводческой эквивалентности между [X X-oм] и [X hin, $\mathrm{X}$ her ] наблюдается и при обращении к немецко-русскому параллельному корпусу. Следовательно, речь идет о некой тенденции, не ограничивающейся направлением перевода, то есть о феномене, который явно выходит за рамки индивидуальных предпочтений переводчика. Во-вторых, семантика.

Обращение к одноязычному немецкому корпусу DeReKo (das Deutsche Referenzkorpus des Instituts für Deutsche Sprache in Mannheim - Институт немецкого языка, Мангейм) показало, что выражения, образованные на основе паттерна [X hin, $\mathrm{X} h e r]$, в отличие от русского [Х Х-ом], редко употребляются в противительной конструкции. Если русская форма $[\mathrm{X} \mathrm{X}-о м]-$ это часть конструкции $[\mathrm{P}(\mathrm{X}$ $\mathrm{X}-о м)$, но/a Q], немецкое выражение [X hin, $\mathrm{X}$ her] само часто вводится усилительной частицей $d o c h$, а после него крайне редко следует клауза, вводимая противительными союзными словами типа aber, doch ${ }^{4}$ или jedoch. Соответствующая пропозиция Q следует за [X hin, X her], как правило, без всякого коннектора. Из 6409 встретившихся в DeReKo употреблений выражения [X hin, X her] только 24 включены в контекст эксплицитного противопоставления с aber, doch или jedoch. Таким образом, русской конструкции [P(X X-oм), но/a $\mathrm{Q}]$ соответствует немецкая [aber/ doch/jedoch $\mathrm{P}(\mathrm{X}$ hin, $\mathrm{X}$ her $), \mathrm{Q}]$, а не [P(X hin, $\mathrm{X}$ her $),$ aber/doch/jedoch $\mathrm{Q}]$, как можно было бы предположить на основе структурного сходства.

Заметим, что противопоставление, часто вводимое союзами но и $a$, может отсутствовать и в употреблениях русской конструкции [X X-ом]. Ср. примеры (3) и (5). В целом, однако, контексты противопоставления, даже и не вводимые

${ }^{3}$ О соотношении понятий системной и переводческой эквивалентности см. [Добровольский 2011].

${ }^{4}$ В случаях, когда $d o c h$ вводит противопоставление, эту лексему принято описывать как союзное слово — грамматический омоним усилительной частицы doch. 
противительным союзом, характерны для русской конструкции [X X-ом]. Так, в примере (3) фраза в другой раз приеду, заберу и пеньку содержательно противопоставлена предшествующей фразе пенька пенькою, которая выражает нежелание Чичикова обсуждать с Коробочкой условия покупки пеньки, то есть является показателем безразличия, как бы выводя этот объект обсуждения из области значимых тем. В примере (5) противительный союз но формально присутствует, однако он вводит противопоставление, относящееся не к непосредственно предшествующей фразе деньги деньгами, а к более раннему контексту, ср.: И не потому, что растут деньги. <..> Но потому, что всё это дело рук твоих. Именно по этой причине пример (5) целесообразно рассматривать в одной группе с (3). В этом случае семантика противопоставления как бы разлита в контексте, но формально паттерн [Р(X X-ом), но/a Q] реализуется не полностью. Наличие или отсутствие эксплицитного противопоставления $\mathrm{P}$, но/ $a \mathrm{Q}$ является значимым моментом для выбора немецкого соответствия. В переводе контекстов эксплицитного противопоставления, вводимого союзами но и $a$, более естественными оказываются конструкции типа [Р(es gibt nun einmal $\mathrm{X})$, aber $\mathrm{Q}]$ или [Р(X ist wichtig $)$, doch $\mathrm{Q}]$. Cp. способы перевода русской конструкции [X X-oм] в примерах (2) и (4): Es gibt nun einmal verschiedene Meinungen, aber Sie sehen ja... и die Verwandten sind wichtig, doch ich reise... Говорящий признает значимость обсуждаемой сущности в первой части высказывания, для того чтобы тут же указать на ее незначимость: ' $\mathrm{X}$ важен, но Q'. Говорящий как бы соглашается с мнением собеседника, чтобы сразу указать на более важные моменты ситуации. Если же эксплицитное противопоставление, вводимое противительным союзом, отсутствует в контексте, конструкция [X X-ом] переводится фразой со значением 'Х неважен'. Ср.: Das Geld ist nicht das Wichtigste. В этом случае уступительность, присущая этой русской конструкции, в переводе теряется.

Отсутствие параллелизма между выражениями, образованными по схеме [X $\mathrm{X}-o м]$, и выражениями на основе паттерна [X hin, $\mathrm{X}$ her] подтверждается и при обращении к немецко-русскому параллельному корпусу. Поскольку этот подкорпус не содержит ни одного примера употребления немецкой конструкции [X hin, X $h e r]$, поиск осуществлялся по русской части на основе тех же параметров и принципов отбора материала, что и в русско-немецком корпусе. Поиск дал следующие результаты:

(6) „Warum sollte er dir Blumen schicken?“ „Wir kennen uns schon lange,“ sagte sie, „und vielleicht verehrt er mich.“ — „Gut,“ sagte ich, ,soll er dich verehren, aber soviel kostbare Blumen, das ist aufdringlich." [Heinrich Böll. Ansichten eines Clowns (1963)]

— <..> Почему, собственно, он послал тебе цветы? - Мы старые друзья, сказала она, - может быть, он мой поклонник. - Очень мило, - сказал я, - поклонник поклонником, но дарить такой большой букет дорогих цветов - значит навязываться. [Генрих Бёлль. Глазами клоуна (Р. Райт-Ковалева, 1964)] 
(7) Wenn er sie erst hat, gibt es nur noch Königsberger Klopse mit deutscher Tunke. Und ich habe keine Sorge, daß Gerda das nicht auch weiß. Trotzdem beschließe ich, mit ihr nach dem Essen zusammen wegzugehen. Vertrauen ist zwar Vertrauen, aber Eduard hat zuviel verschiedene Liköre in der Bar. [Erich Maria Remarque. Der schwarze Obelisk (1956)]

Когда он ее получит, ей опять будут подавать только битки по-кенигсбергски с немецким соусом. И я уверен, что Герде это тоже известно. И все-таки я решаю после ужина уйти вместе с нею. Доверие - доверием, но у Эдуарда в погребке слишком много крепких напитков. [Эрих Мария Ремарк. Чёрный обелиск (В. Станевич, 1961)]

(8) „Hast du beachtet, wie sie grüßte? Beinahe gar nicht. Dabei war meiner unmaßgeblichen Ansicht nach ihr Hut ganz unmäßig geschmacklos..." „Na, was den Hut betrifft... Und mit dem Grüßen warst du wohl auch nicht viel entgegenkommender, meine Liebe. Übrigens ärgere dich nicht; das macht Falten.“ [Thomas Mann. Buddenbrooks (1896-1900)]

Ты заметил, как она поклонилась? Едва-едва кивнула. И потом, с моей точки зрения, впрочем ни для кого не обязательной, ее шляпа верх безвкусицы. - Ну, шляпа шляпой... а что касается поклона, то и ты была не слишком любезна, дорогая моя! Не сердись, Тони, это старит... [Томас Манн. Будденброки (Н. Ман, 1953)]

Примеры (6)-(8), с одной стороны, подтверждают наше наблюдение, что в контексте эксплицитно выраженной противительности немецкий язык предпочитает не конструкцию [X hin, X her], а другие выражения; cp. soll er dich verehren, aber... - поклонник поклонником, но...; Vertrauen ist zwar Vertrauen, aber... - доверие - доверием, но... С другой стороны, эти примеры позволяют предположить, что русская форма [X X-ом] более употребительна, чем немецкая [X hin, $\mathrm{X}$ her]. Русское выражение [X X-ом] появляется в тексте перевода и в случаях, когда оригинал не содержит стимула, который в силу формальных особенностей мог бы спровоцировать употребление данного выражения. Так, вполне можно себе представить в качестве адекватного перевода фразы soll er dich verehren, aber... (6) формально более близкую к синтаксису оригинала фразу пусть он даже и твой поклонник, но... Выбор Райт-Ковалевой мотивирован, по-видимому, интуитивным ощущением большей укорененности паттерна [X X-ом] в узусе и, соответственно, его большей идиоматичности. Немецкая конструкция, употребленная в оригинальном тексте примера (6), также основана на паттерне с высокой степенью идиоматичности: [soll SUBJ OBJ V] в значении допущения, которое в следующей клаузе, вводимой союзным словом aber, признается нерелевантным. Таким образом, перевод в примере (6), далекий от оригинала по структуре, оказывается хорошим функциональным эквивалентом, поскольку и та и другая формы, вводя в дискурс допущение истинности пропозиции, семантически вынуждают последующее противопоставление. К тому же обе эти формы характеризуются высокой частотностью в узусе и выражают идею безразличия говорящего по отношению 
к обсуждаемому положению вещей; ср. близкое по семантике высказывание Мнето какая разница, поклонник он твой или нет. Ср. также пример (7), в котором обе формы Vertrauen ist zwar Vertrauen, aber... и доверие - доверием, но... близки и семантически, и функционально 5 . Вопрос, почему в немецком оригинале употребляется конструкция [X ist zwar $\mathrm{X}]$, а не теоретически возможная конструкция [X hin, $\mathrm{X} h e r]$, объясняется не только авторским выбором, но и узуальными ограничениями на заполнение слота X в конструкции [X hin, X her]. В корпусе DeReKo не обнаруживается ни одного примера выражения Vertrauen hin, Vertrauen her и есть лишь один пример на употребление лексически близкого выражения; ср. Gottvertrauen hin, Gottvertrauen her (источник: Z80/SEP.00291 Die Zeit, 19.09.1980, S. 69; Zeitlese). Сходным образом, теоретически возможное в примере (6) Verehrer hin, Verehrer her оказывается не закрепленным в узусе: в DeReKo на такое словосочетание не нашлось ни одного примера. Пример (8) интересен тем, что в немецком оригинале полностью отсутствует значение уступительности, характерное для русской конструкции [X X-ом]. Cp. Na, was den Hut betrifft... vs. Hy, шляпа шляпой... Потенциально возможное в этом контексте выражение Hut hin, Hut her, с одной стороны, совершенно не характерно для стиля Томаса Манна, a c другой - недостаточно укоренено в узусе. B DeReKo встретился всего один контекст, и тот — как элемент языковой игры: [...] daß der Kanzler nicht seinen feschen kanadischen Cowboyhut trug. Auf diesen scherzhaften Ton ging der Kanzler schlagfertig ein und sagte: Hut hin, Hut her - Hauptsache, die Opposition zwinge ihn nicht eines Tages, seinen Hut zu nehmen (источник: Z77/JUL.00351 Die Zeit, 22.07.1977, S. 5; Schmidt bei Carter: Nützlich und offen).

\section{$* * *$}

Наличие в том или ином языке лексических единиц и конструкций, близких по значению и прагматическим характеристикам, всегда ведет к существенной вариативности в формулировании заданного смысла. Такая ситуация имеет место как в русском, так и в немецком языке при выражении смыслов, связанных со снижением релевантности аргумента собеседника, с незначимостью для говорящего тех или иных аспектов обсуждаемого положения вещей и т. п. Несколько условно единицы, выражающие эти смыслы, можно назвать «показателями безразличия». Тот факт, что структурно схожие показатели безразличия русского и немецкого языков редко используются в переводе, объясняется целым рядом факторов. Во-первых, выбор способа перевода заданного смысла может зависеть от индивидуальных предпочтений переводчика. Во-вторых, значимыми факторами оказываются стилистические ограничения и конвенции узуса, в частности максимально близкие по форме и значению конструкции сопоставляемых языков могут отличаться друг от друга степенью употребительности. В-третьих, межъязыковые различия могут

${ }^{5}$ Возможный альтернативный вариант перевода фразы Vertrauen ist zwar Vertrauen, aber... с помощью доверие - это, конечно, хорошо, но... был бы более близок к оригиналу по форме, но вряд ли обнаруживает серьезные функциональные преимущества. 
объясняться особенностями сочетаемости. В работах по грамматике конструкций неоднократно подчеркивалось, что любая конструкция может быть частью некоторой другой, большей конструкции, что влияет на семантику и прагматику этой встроенной конструкции. Так, русская конструкция [X X-ом] в стандартном случае встраивается в контекст эксплицитного противопоставления, становясь частью уступительно-противительной конструкции $[\mathrm{P}(\mathrm{X} \mathrm{X}-о м)$, но/ $a \mathrm{Q}]$ со значением 'для выполнения Q есть важные аргументы, несмотря на ослабляющее Р'. Для немецкой конструкции [X hin, X her] контексты противопоставления, вводимые такими союзными словами, как aber, doch или jedoch, нехарактерны. И наконец, межъязыковые контрасты могут зависеть от предпочтений в заполнении свободного слота $\mathrm{X}$. Хотя на первый взгляд позиция X может заполняться практически любым существительным, анализ больших корпусов типа DeReKo показывает, что здесь существуют явные ограничения.

\section{Литература}

Апресян В.Ю. Уступительность: механизмы образования и взаимодействия сложных значений в языке. М. : Языки славянской культуры, 2015. 288 с.

Баранов А.Н., Добровольский Д. О. Основы фразеологии (краткий курс). М. : Флинта : Наука, 2013. 312 с.

Бульгина Т.В., Шмелев А.Д. Языковая концептуализация мира (на материале русской грамматики). М. : Школа «Языки русской культуры», 1997. 576 с.

Голубиов С.А. Семантика и прагматика показателей безразличия: сопоставительный аспект: дис. ... канд. филол. наук / Кубанский гос. технологический ун-т. Краснодар, 1999. 210 с.

Добровольский Д.О. Сопоставительная фразеология: межъязыковая эквивалентность и проблемы перевода идиом // Русский язык в научном освещении. 2011. №2 (22). С. 219-246.

Добровольский Д.О. Грамматика конструкций и фразеология // Вопросы языкознания. 2016. №3. С. 7-21.

Шмелев Д. Н. О «связанных» синтаксических конструкциях в русском языке // Шмелев Д.Н. Избранные работу по русскому языку. М. : Языки славянской культуры, 2002. С. 413-438.

Černyševa I.I. Phraseologie // Stepanova M.D., Černyševa I.I. Lexikologie der deutschen Gegenwartssprache. 2. Aufl. Moskva : Vysšaja škola, 1986. S. 175-230.

Dobrovol'skijD. Phraseologie undKonstruktionsgrammatik//Konstruktionsgrammatik III. Aktuelle Fragen und Lösungsansätze / Alexander Lasch, Alexander Ziem (Hrsg.). Tübingen : Stauffenburg, 2011. S. 111-130.

Dobrovol'skij D. On the systematic variation of German idioms: Converse pairs as a constructional phenomenon // Journal of Social Sciences. 2015. Vol. 11. No. 3. P. 248257.

Fleischer $W$. Phraseologie der deutschen Gegenwartssprache. 2. durchges. u. erg. Aufl. Tübingen : Niemeyer, 1997. 


\section{Электронные ресурсы:}

НКРЯ - Национальный корпус русского языка. URL: http://www.ruscorpora.ru DeReKo - Das Deutsche Referenzkorpus des IDS Mannheim im Portal COSMAS II (Corpus Search, Management and Analysis System). URL: https://cosmas2.idsmannheim.de/cosmas2-web>

\section{O. Dobrovol'skij}

V.V. Vinogradov Russian Language Institute, Russian Academy of Sciences, Instutute of Linguistics, Russian Academy of Sciences

(Russia, Moscow)

dobrovolskij@gmail.com

\section{"INDICATORS OF INDIFFERENCE" IN THE RUSSIAN-GERMAN PARALLEL CORPUS}

The purpose of this study is to reveal to what extent the intuitive ideas of the equivalence of structurally similar German and Russian constructions correspond to their actual use. The empirical data are based on the Russian-German and German-Russian parallel corpora of the RNC (Russian National Corpus). We analyze such constructions as rodstvenniki rodstvennikami, no... 'relatives are relatives but...', mneniya mneniyami, a... 'opinions are opinions but...', i.e. phrases structurally based on the pattern [P(X X-om), no/a Q] 'X is X but Q'. Somewhat simplifying, such constructions can be labelled as "indicators of indifference", because using this structure, the speaker puts the entity X outside the scope of relevant issues of discussion. Specific semantic features may come to the fore, such as downshifting of the relevance of the argument of the interlocutor or disagreement with his or her proposal, the purely concessive meaning or indifference of the speaker with regard to objective circumstances. At first glance, the pattern $[\mathrm{P}(\mathrm{X} X-\mathrm{om})$, $n o / a \mathrm{Q}]$ ' $\mathrm{X}$ is $\mathrm{X}$ but $\mathrm{Q}$ ' has an equivalent in German, that is very close in both form and meaning, namely the constructional phraseme [X hin, $\mathrm{X}$ her $]$. The analysis allowed us to conclude that there is no functional equivalence between these structures. Their parallel use in authentic contexts from the RNC is extremely atypical. The present article discusses the reasons for the lack of functional equivalence between the analyzed constructions.

Key words: parallel corpus, lexical semantics, constructions, cross-linguistic equivalence, Russian, German.

\section{References}

Apresyan V.Yu. Ustupitel'nost': mekhanizmy obrazovaniya i vzaimodeystviya slozhnykh znachenii v yazyke [Concessiveness: mechanisms of formation and interaction of complex meanings in the language]. Moscow, Yazyki slavyanskoi kul'tury Publ., 2015. 288 p. (In Russ.) 
Baranov A.N., Dobrovol'skij D. O. Osnovy frazeologii (kratkii kurs) [Foundations of phraseology (a brief course)]. Moscow, Flinta, Nauka Publ., 2013. 312 p. (In Russ.)

Bulygina T.V., Shmelev A.D. Yazykovaya kontseptualizatsiya mira (na materiale russkoi grammatiki) [Language conceptualization of the world (on the basis of the Russian grammar)]. Moscow, Shkola "Yazyki russkoj kul'tury" Publ., 1997. 576 p. (In Russ.)

Černyševa I. I. Phraseologie. Lexikologie der deutschen Gegenwartssprache / Stepanova M.D., Černyševa I. I. 2. Aufl. Moskva, "Vysšaja škola" Publ., 1986, pp. 175-230.

Dobrovol'skij D. Phraseologie und Konstruktionsgrammatik. Konstruktionsgrammatik III. Aktuelle Fragen und Lösungsansätze / Alexander Lasch, Alexander Ziem (Hrsg.). Tübingen, Stauffenburg, 2011, pp. 111-130.

Dobrovol'skij D. On the systematic variation of German idioms: Converse pairs as a constructional phenomenon. Journal of Social Sciences, 2015, vol. 11, no. 3, pp. 248257.

Dobrovol'skij D. O. [Contrastive phraseology: cross-linguistic equivalence and translation of idioms]. Russkii yazyk v nauchnom osveshchenii, 2011, no. 2 (22), pp. 219-246. (In Russ.)

Dobrovol'skij D. O. [Construction Grammar and phraseology]. Voprosy yazykoznani$y a, 2016$, no. 3, pp. 7-21. (In Russ.)

Fleischer W. Phraseologie der deutschen Gegenwartssprache. 2. durchges. u. erg. Aufl. Tübingen, Niemeyer, 1997.

Golubtsov S. A. Semantika i pragmatika pokazatelei bezrazlichiya: sopostavitel'nyi aspekt. Diss. kand. filol. nauk [Semantics and pragmatics of indifference indicators: a contrastive aspect. Cand. of philology diss.] / Kubanskii gos. tekhnologicheskii universitet. Krasnodar, 1999. 210 p. (In Russ.)

Shmelev D. N. [On "bound" syntactic constructions in Russian]. Izbrannye raboty po russkomu yazyku [Selected works on the Russian language]. Moscow, "Yazyki slavyanskoi kul'tury” Publ., 2002, pp. 413-438. (In Russ.) 